\title{
A RESEARCH OF CONSTRUCTION MECHANISM OF VASSAL STATE'S CITY GROUP DURING SPRING AND AUTUMN PERIOD BASED ON THE ANALYZATION OF GEOGRAPHIC IMAGE

\author{
—Take South Region of Shandong as Example
}

\author{
Xing $\mathrm{GAO}^{\mathrm{a}}$, Baihao $\mathrm{LI}^{\mathrm{a}}$, Xiaodi $\mathrm{ZHOU}^{\mathrm{a}}$ \\ ${ }^{a}$ Architectural School, Southeast University, Nanjing China - xinggaoseu@ gmail.com
}

KEY WORDS: Urban History of China, City group, Construction mechanism, South region of Shandong, Spring and Autumn Period

\begin{abstract}
:
Spring and Autumn period, the vassal states began to carry out country defense construction actively, brought changes to building the ideological. At that time, the south region of Shandong, as an independent unit of geography, seldom affected by external factors, and had striking cultural characteristics. Vassal states there constructed their capital mainly to defense the neighboring countries and cope with small scale mergers war, not involving the nationwide military deployment. Therefore, the region reflect the construction thought changes during the Spring and Autumn Period, and consistent with the research purpose. Based on this judgment, the author analyzed each capital's location and terrain feature by topographic map. In brief, the Spring and Autumn Period, feudal states acted of one's own free will, the relationship between cities contained the one within and between vassal states. Within vassal state relationships included economic support, entrenching each other and protecting the country together. Meanwhile, strategic defensing, scrambling for resources and geographical location comprised of the competition between vassal states. In the agrarian age, the political centers and agricultural areas were interdependent, giving priority to the development of political cities. Transformation of capitals' space layout was actually the process of carving up farming plains, the powerful states occupy favorable geographical position, and the small countries would be encroached and annexed gradually.
\end{abstract}

\section{INTRODUCTION}

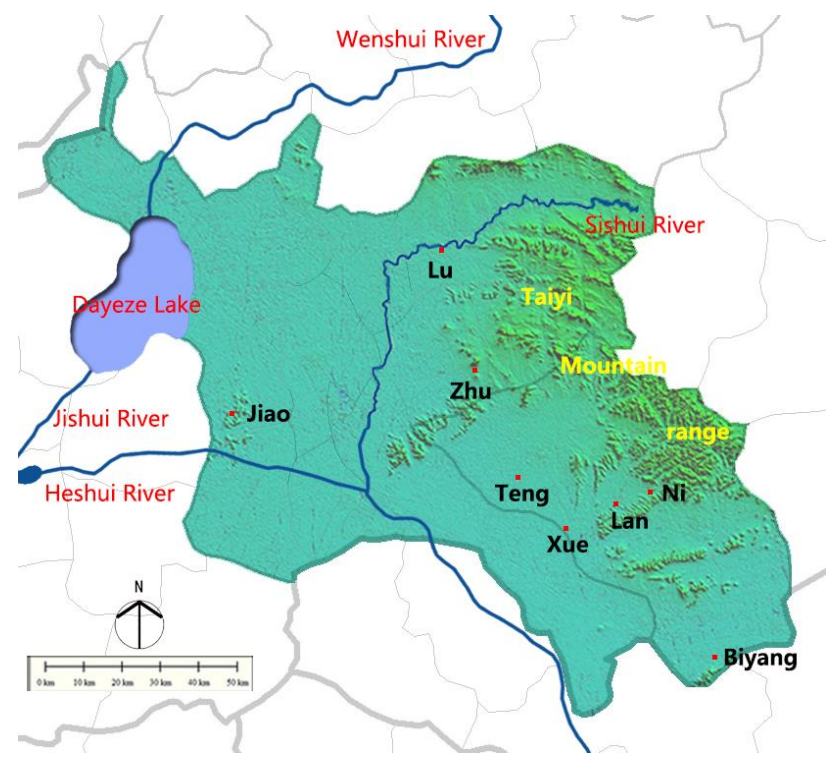

Figure 1. The layout of states during the Spring and Autumn Period and Warring States Period in south region of Shandong

In Spring and Autumn period, Weishan Lake was not existent, and the lake bed now was a valley, through where Sishui River flowed into Huaihe River. Without Weishan Lake to obstruct the traffic from west to east, there was a relatively independent geographical unit -- the south region of Shandong, with Dayeze Lake and Nanwanghu Lake formed the west boundary, and Taiyi mountains on the east side (Yuzhen Yang, 2008a; Yongsheng Guo, 1990a). According to Cultural Relics Atlas China (Shandong Volume) (State Administration of Culture Heritage, 2009) and The Distribution Table of Ancient City and
Country in Shandong (Shang--Nanyan) provided by Shandong Provincial Bureau of cultural relics, the author collected a total of eight vassal states ${ }^{1}$ of Spring and Autumn Period in this region, as the research object (Fig. 1). At that time, vassal states began to carry out country defense construction actively, brought changes to building the ideological.

Among the eight states, State $\mathrm{Lu}$ and Zhu were strongest, other were weak power. In the early Spring and Autumn Period, Zhu became strong gradually through a set of annexation war, "(Zhu) expanded and not resigned to playing second fiddle.... Lu played his biggest enmity, who was contiguous to Zhu on north, east and northwest."(Xiantang Wang, 2007) However, after years of war and chaos, large tracts of land had been swallowed up by $\mathrm{Lu}$, and State Lan betrayed Zhu to pledge allegiance to Lu. Up to late Spring and Autumn Period, Zhu suffered decline in national strength, as the territory reduced greatly. So as other little country, State Jiao was extinguished by $\mathrm{Lu}^{2}$, State Biyang was destroyed by allied forces of thirteen nations. After that, Lu was immersed in minister dictatorship, the monarch lost power of self-defense. In a word, all the states around Sishui River went downhill and died out one by one, as new external forces rose in Warring States Period. The map of Three Zhu's territory situation drew by Xiantang Wang summarized the territorial division of the Spring and Autumn Period (Fig. 2).

As an independent unit of geography, the south region of Shandong seldom affected by external factors, and had striking cultural characteristics. Vassal states there constructed their capital mainly to defense the neighboring countries and coped with small scale merger war, not involving the nationwide military deployment. Therefore, the projects reflect the

\footnotetext{
${ }^{1}$ State Xiaozhu (Ni) and State Lan (Changlv) were separated from Zhu, general designated "Three Zhu".

${ }^{2}$ In addition, another theory is State Jin destroyed Biyang.
} 
construction thought changes during Spring and Autumn Period, and consistent with the research purpose.

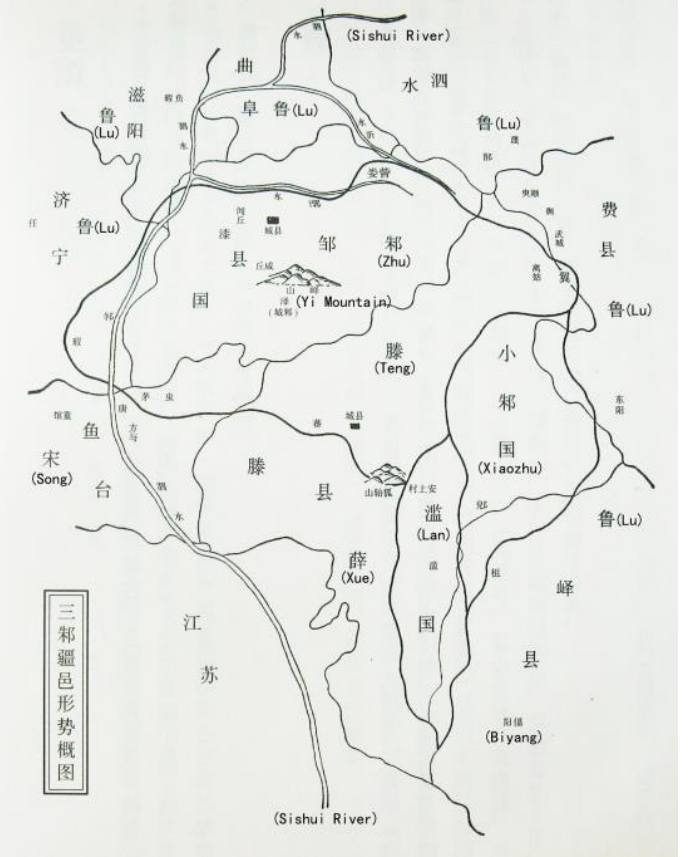

Figure 2. Frontier situation map of "Three Zhu"

\section{CITY GROUP SEPARATED BY VASSAL STATES}

The spring and Autumn period and the Warring States Period, territory meant a series of single cities and farming area around each of them. Although the land and people belonged to the emperor, kings of vassal states enjoyed the use right and management right, and utilized them to pursued power and reputation eagerly. As a result, Cities within a vassal state united together and fought against each other as a group. Within a group, strategic layout of each city and relationship between them determined the allocation of resources, integrated defense, supply, development and so many problems. If comprehensive national strength contrast or situation of the area changed, the relations of city group must adjust accordingly. Meanwhile, era background and regional culture also had certain influence. Capital city was the center of every group, as while as the center to against other state, consequently, the strategic layout of capitals could best embody the effect of internal vassal state relations and exterior on the construction mechanism. This section took all the capital cities located in the south region of Shandong as example to carry on the discussion.

\subsection{Lu's Qufu: A Myriad of Stars Surround the Moon.}

Qufu laid on west side of the low hilly land in the middle of Shandong, controlled large tracts of fertile agricultural plain stretched west to the east coast of Dayeze Lake, adjacent to the traffic artery--Sishui River. The broad plain on the west provided economic support, where little plain cities were located, such as Xiaqiu and Zhongdu. The hilly region on the east was the military deployment area, where three military cities were arranged, included Bian (Bian city ruins), Wu (Xiaochengzi city ruins) and Huangyue (Chengziwo city ruins); all have ruins left today. Indicate the brilliance of Qufu's site selection.

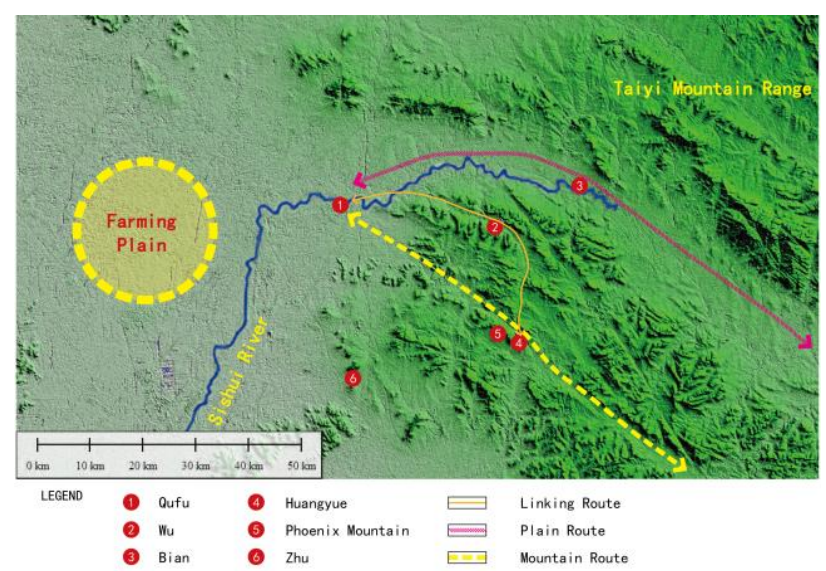

Figure 3. The situation analysis of Qufu

Three defense cities, with disparate strategic significance, crowded together and depended on each other: $\mathrm{Wu}$ and Huangyue were military stronghold with difficult terrain and function, and Bian was an extremely important forward post (Fig. 3). Wu was located on a platform surrounded by Longwantao set of reservoir, facing water three sides and no direct foreign traffic, which was easy to keep and difficult to attack. In macro view, the city could be cooperative engagement with other cities or serve as final fortress, as it was situated in the middle of Qufu and other two cities (Fig. 4-6).

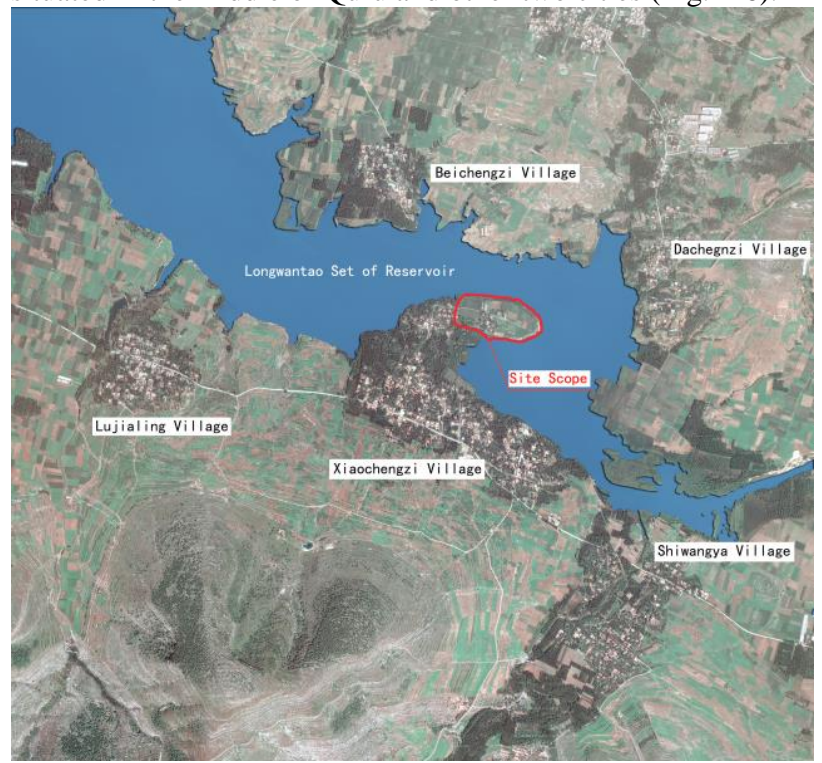

Figure 4. The topographic map of $\mathrm{Wu}$

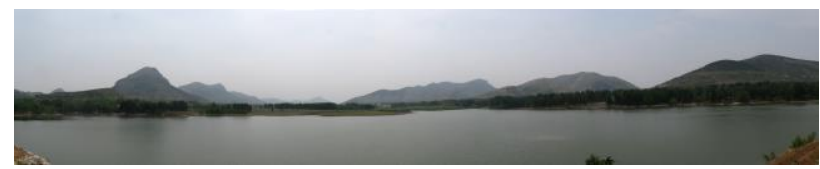

Figure 5. The environment figure of $\mathrm{Wu}$

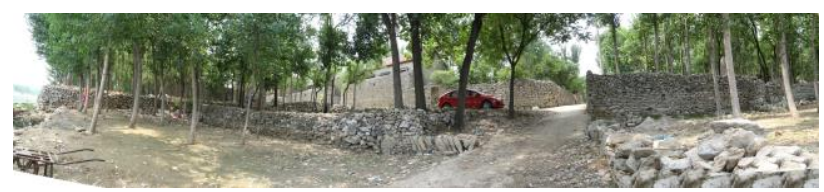

Figure 6. The panoramic view of the entrance of $\mathrm{Wu}$

Back against the mountain, Huangyue was located on a platform in a valley beside a mountain route through the hilly region to Qufu directly; guarded and commanded the route, with the main peak of Phoenix Mountain as beacon tower and 
farming plain surrounded by Phoenix Mountain as supply area (Fig. 7-8). Bian was located in the strip plain through the mountain area, near the source of Sishui River, with two routes to Qufu waterway and land way. Although there was no dangerous terrain, it had the effect of outpost to warning Qufu dangerous. To sum up, the three cities whose location not only paid attention to its own defense but also the mutual support connected into a system by different levels of route to protect capital.

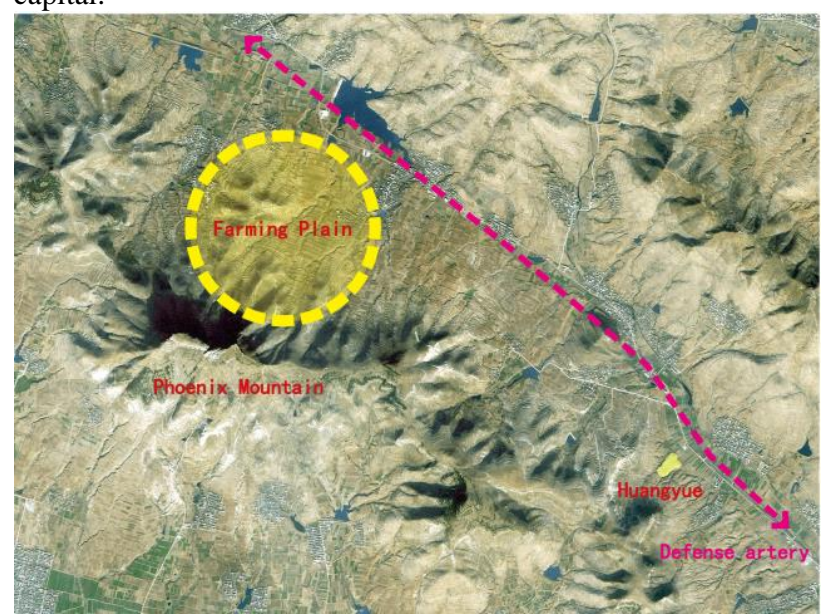

Figure 7. The topographic map of Huangyue

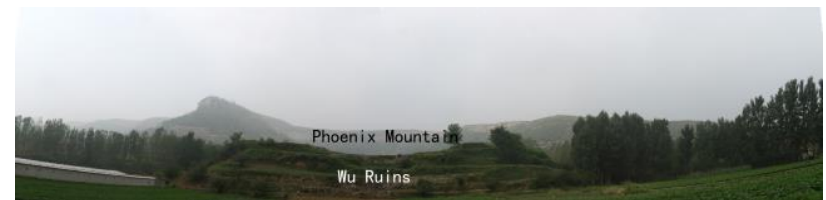

Figure 8. The relationship between Huangyue and Phoenix Mountain

Records of Yanzhou Province - biography of Vassal States 《充州府志・国纪志》, twenty-four year of Wanli edition in Ming dynasty, records "Duyu said, City Wu located at south side of Bian, as to take precautions against Zhu." It showed that $\mathrm{Wu}$ was built to defense Zhu. As for Bian, Geographical Pattern Recorded of Previous Dynasties -Yanzhou Province (Vol.32) 《读史方舆纪要・充州府》 records “Seventeen year of Lord Xi (643 B.C.), Mrs. Jiang met Lord of Qi at Bian. Twenty-nine year of Lord Xiang (544 B.C.), Jiwuzi occupied Bian." In consideration of historical records and Bian's location $^{3}$, it presumed to prevent Qi from Westward. There were not specific records for Huangyue, but according to the geographical location, it supported to guard the arteries from Qufu to the south-east. In brief, three cities constitute a comprehensive defense system against all forces around.

Careful protection and superior geographical environment made $\mathrm{Lu}$ the most sustainable state in the region at that time. However, along with the escalating of merger warfare, Lu declined unavoidably. When the comprehensive national strength is not enough to support culture prosperity, the state of etiquette may also be destroyed.

\subsection{Zhu's Decision: Relocate Capital to Seize Power.}

Annalistic Records - clan section 《通志・氏族略》 of song dynasty accounted "The ancient Zhu was located $20 \mathrm{~km}$ southeast of Xianyuan in Yanzhou." Xianyuan used to be the name of Qufu in Song Dynasty. The spring and Autumn Annals
《左传》 accounted "Thirteen year of Lord Luwengong (614 B.C.), Lord Zhuwengong moved to Yi after divination." This proved Zhu was moved from $20 \mathrm{~km}$ southeast of Qufu to Yishan in Zhoucheng. The Vassal States Map of Yanzhou in Spring and Autumn Period 《春秋府境列国图》 recorded by Records of Yanzhou Province 《充州府志》 depicted the relative situation of Zhu and Lu, in the early years. The red Zhu (制) added by author showed the capital relocated (Fig. 9).

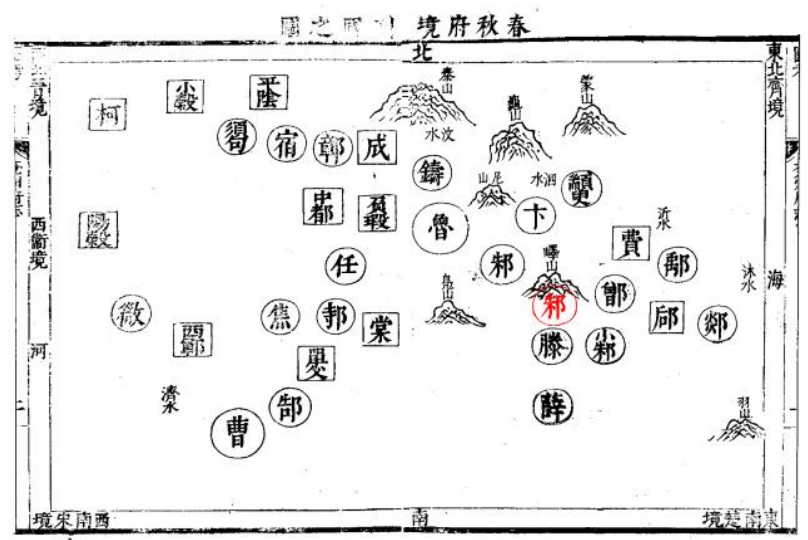

Figure 9. The Vassal States Map of Yanzhou in Spring and Autumn Period

As Lu was the biggest enmity, Zhu's Decision of Relocating Capital was most likely threatened by $\mathrm{Lu}$. The former position of Zhu surrounded by hills and mountains did have certain defensive function, but limited the supply plain controlled by capital directly, restricted his development, and too close to Lu. Moving capital solved this problem geographically (Fig. 10).

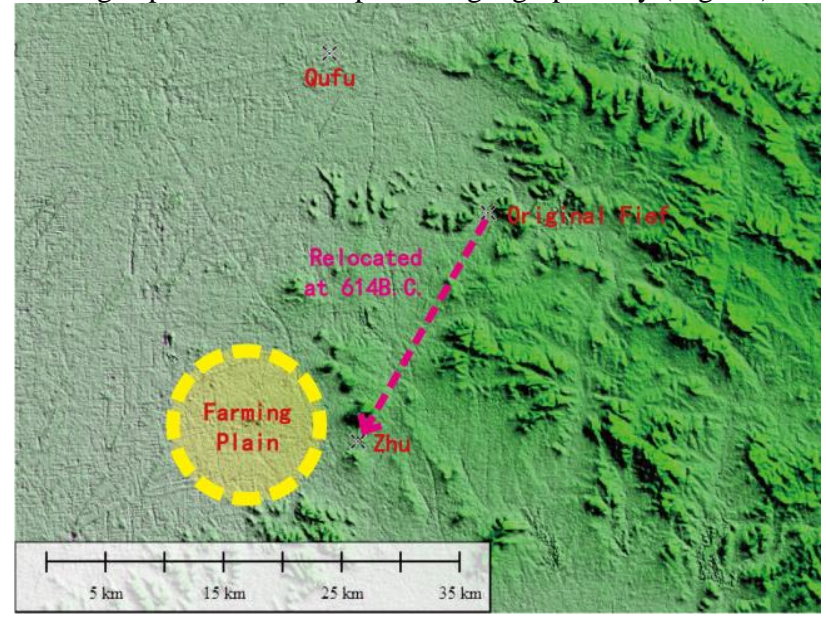

Figure 10. The situation analysis of Zhu's two capitals

The latter position of Zhu was $32.42 \mathrm{~km}$ far from $\mathrm{Lu}$ and harbored great strategic significance. The city was located in between two hills, quite difficult to conquer with Mountain Yi as the north wall and the south wall wind its way along the Mountain Kuo's ridge (Fig. 11-13). Moreover, both Yi and Kuo were isolated mountains on the plain with wide field of vision, enabled the country both good defensive performance and large agricultural plain supplement.

\footnotetext{
${ }^{3}$ Bian was located in the northeast border of $\mathrm{Lu}$, near Qi.
} 


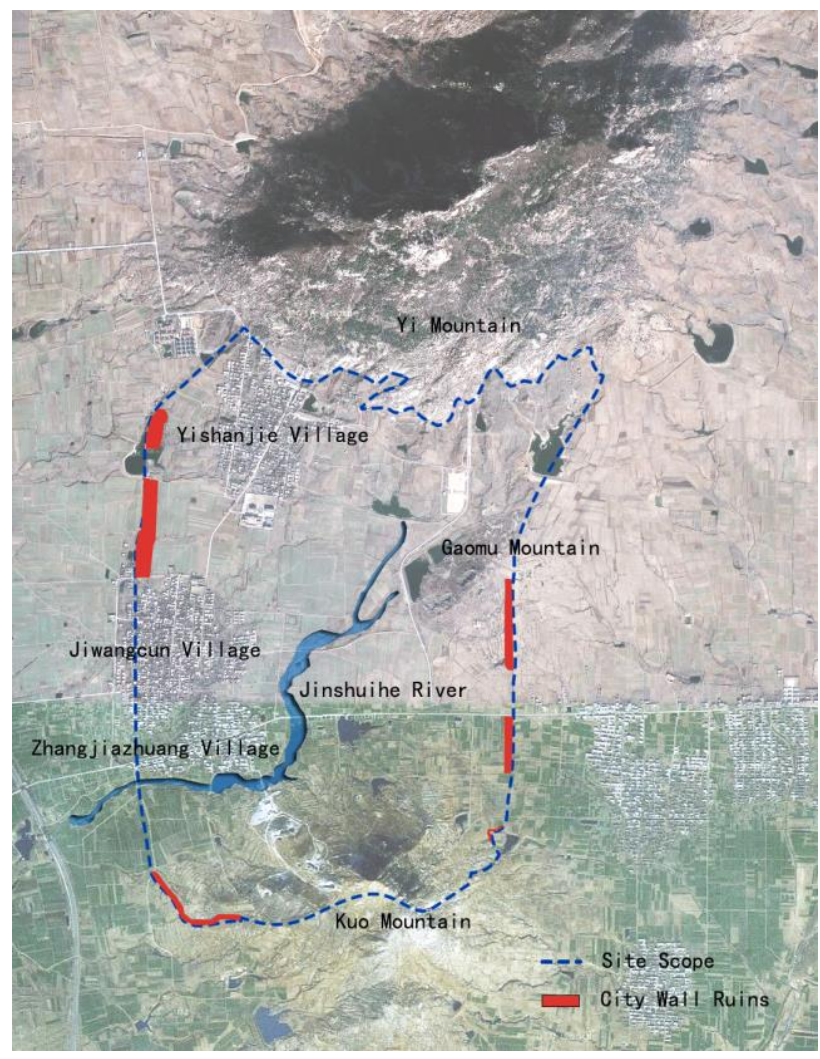

Figure 11. The topographic map of Zhu

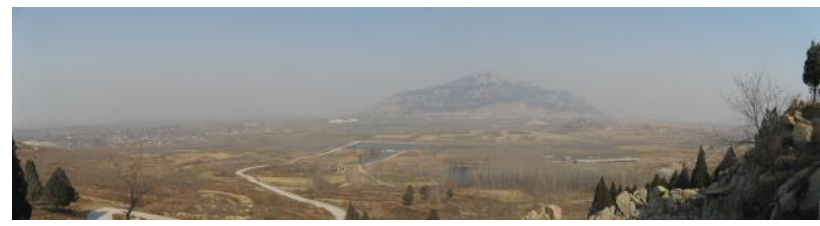

Figure 12. Panoramagram of city Zhu and Yi Mountain

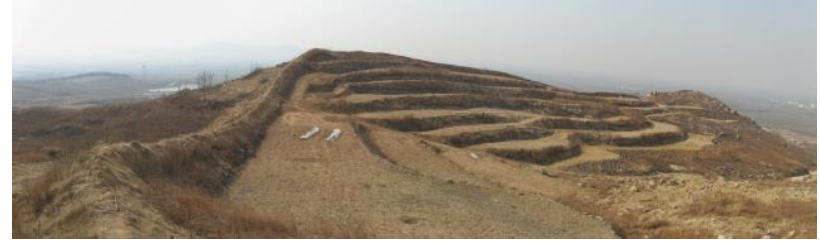

Figure 13. The remains of the city wall on Kuo Mountain

Huo River severed as boundary between Zhu and Lu, Lu used to grab land when Huo River diverted. After moving, Zhu disinclined to show weakness and became the strongest force fighting with Lu. Illustrated the development brought by moving.

Zhu Ruins is very impressive, but facing with great threat. Now both side of Mountain kuo have a cement factory, digging sand and excavating stones, caused serious damage to the landform and landscape of cultural ruins. The cement factory on the west side has a large excavator operating, which have already endangered the wall in the mountain (Fig. 14-15). And even worse, the cement factory on the other side digged a huge hole right on the southeast counter of the city wall (Fig. 16). Need to do something to save the cultural heritage in an urgent manner.

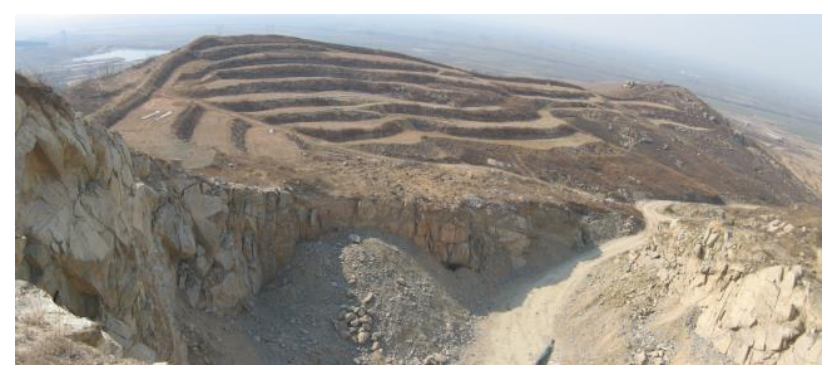

Figure 14. The relationship between the wall and digging hole in Kuo Mountain

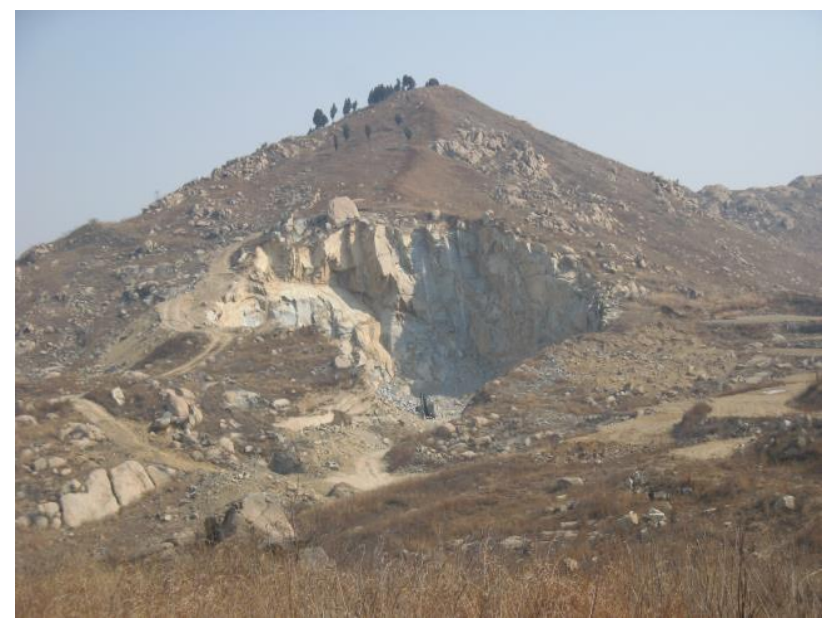

Figure 15. Panoramagram of digging hole in Kuo Mountain

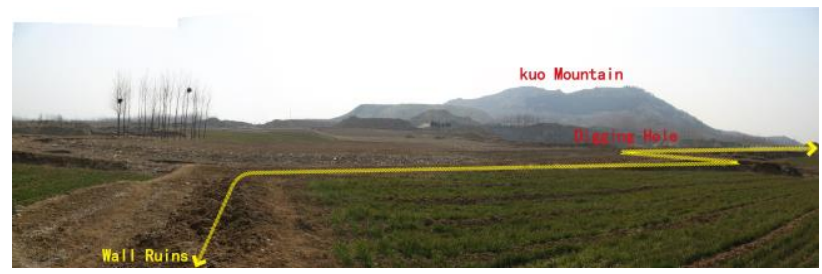

Figure 16. The relationship between the southeast corner of the wall and digging hole

\subsection{Xiaozhu's Choose: Relocate Capital for Self-insurance.}

The first king of Xiaozhu named Yanyou, whose fief was ancient State Ni, so Xiaozhu also named Ni after toponym. The fourth king named Nililai depended on Qi to get viscountcy. Yet after obtained honor, Xiaozhu had to relocate capital under pressure, as a weak power and adjoined with $\mathrm{Lu}$ and Zhu.

Ancient State Ni left Tucheng ruins II, and the latter capital was Ni ruins. As Fig. 17 shows, Tucheng ruins II were located in the plains and controlled wider range of hinterland. On the contrary, $\mathrm{Ni}$ ruins were located on the edge of mountains, limited by Changlv of State Lan, seldom harbored any supply plain. However most important of all, Ni ruins inserted into Mountain and sat on farming basin; due to topography, greatly improved defensive performance than before. 


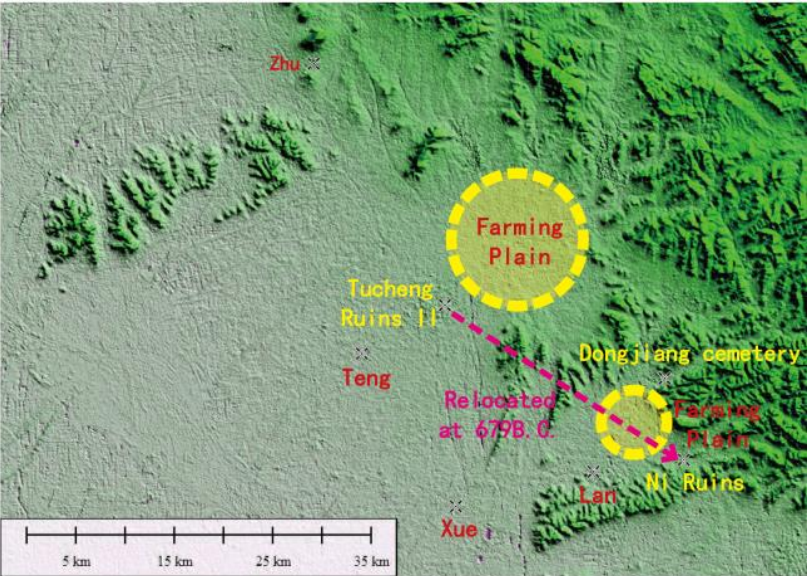

Figure 17. The situation analysis of Xiaozhu's two capitals

There was a cemetery at Dongjiang, not far from Ni ruins. Archaeological report indicated Dongjiang cemetery buried tombs of kings of Xiaozhu included Yanyou. And the cemetery was $8.4 \mathrm{~km}^{4}$ far from Ni ruins and $23.5 \mathrm{~km}$ apart from Tucheng ruins II, which meant pervious monarch was interred near the latter capital. Historical Records -- Biography of Sunzi 《史记 - 孙子列传》 announced “One day march of fifty kilometers may bring death to general; twenty-five kilometers a day will drop half soldiers out." Furthermore, Proper distance for one day march was about fifteen kilometers. It signified $23.5 \mathrm{~km}$ far could not be finished in one day sacrificial ceremony. However, in the Pre-Qin period people sacrificed to ancestors in the form of ancestral temple, mausoleum sacrifice was gradually mature During Han dynasty (Baizhong Wang, 2000a). Take Lu for example, Kancheng cemetery is $61.3 \mathrm{~km}$ apart with Qufu, far more beyond one day match distance. Therefore, Dongjiang cemetery had not been moved at all. Author presumed that Yanyou considered persistence and security to choose the graveyard, finally decided to hide in the mountains; Nililai relocated the capital and retreated to forefather's graveyard, abiding by filial piety and bringing peace force to set the country.

In short, no matter how much resources wasted by moving the capital, Xiaozhu earned honor but lose geographical advantage reflecting the trend of pursuit of fame during Spring and Autumn Period. Two thousand years passed, Tucheng ruins II have already disappeared under the tall buildings of modern city (Fig. 18), but Ni ruins still stand in the natural environment, because of the inaccessible position (Fig. 19). Proved Tucheng ruins II are more suitable for economic development than $\mathrm{Ni}$ ruins.

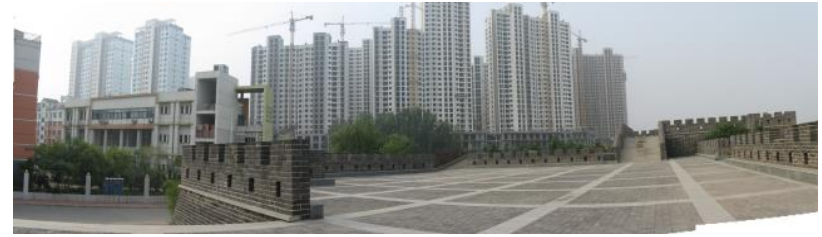

Figure 18. The current situation of Tucheng ruins II

\footnotetext{
${ }^{4}$ Because of a shortage of archaeological data, the site boundary definition is indistinct. So the distance from site to site estimated fuzzily as the distance between the site centers. Similarly hereinafter.
}

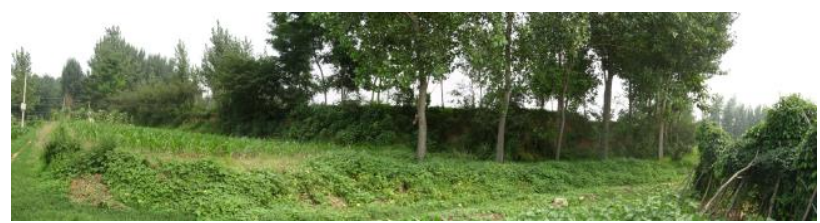

Figure 19. The current situation of Ni ruins

\subsection{Lan's Helplessness: Congenital Deficiency.}

Lan was the weakest state in Three Zhu, with poor territorial geographical environment and no title at all. In terms of macroscopic geographical landscape, Capital Changlv was located in the plains between two mountain ranges in east-west direction, with Xiaozhu on the east and Xue on the west; four sides suffocated and hinterland range was limited, which made it a congenital deficiency small country (Fig. 20).

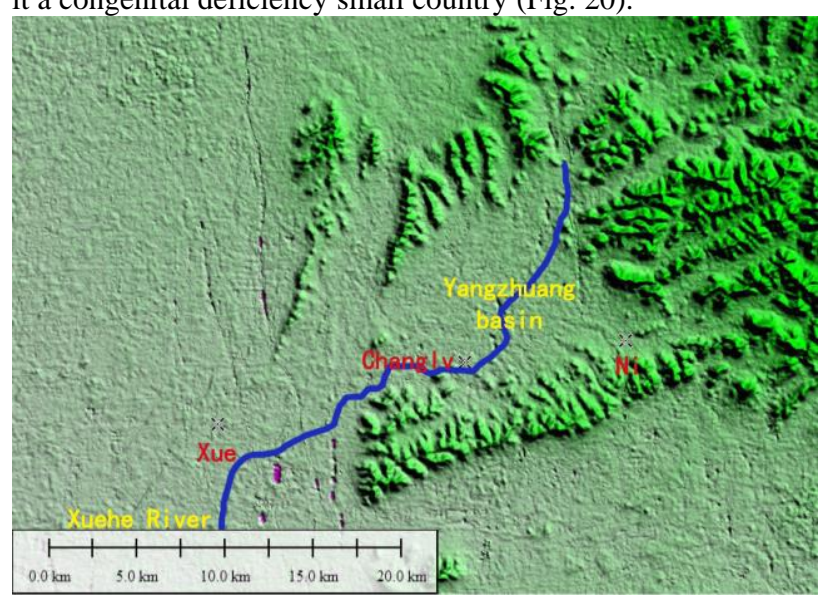

Figure 20. The situation analysis of Changlv

Besides that, Changlv was located on the north bank of Xuehe River within Yangzhuang basin, where the river had a steep bend. The watercourse was resistance by mountains on both sides at the basin exit, once flood discharged would lead to great disaster. The ancients set water level warning label to monitor flood in place like this, and the original meaning of "Lan" was "warning water level", also meant inundation. Limited hinterland and threatened by flood illustrated insufficient national foundation (Fig. 21).

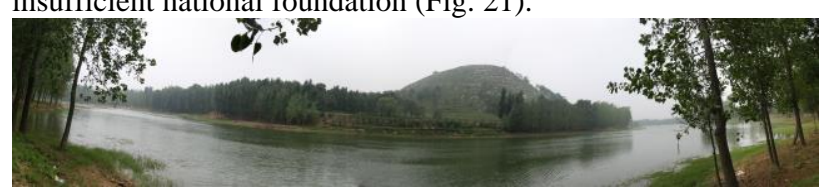

Figure 21. The Xuehe River on the south

The generation of Lan was "Shushu gave throne to Xiafu and moved to Lan". There were several versions of this history. From the perspective of the geographical condition of Lan, Shushu gave up throne and chose such a poor location, either because of the failure in court battle or his honest virtue. After Zhu became weak, under the background of the jungle law in the Spring and Autumn Period and the limited condition, Lan paid allegiance to $\mathrm{Lu}$. It is understandable for Lan to cling to power in order to survive.

\subsection{Biyang and Jiao: Perish Earliest in the Chaos of Local}

Both Biyang and Jiao situated on the edge of the research scope (Fig. 22), with similar geographic patterns and similar fate. Biyang was located in the southernmost part of study area, in connection with the central plains area and Qi (Shandong 
Peninsula); perished earliest and its land passed from Song to Qi. Jiao situated on the connecting channel between the central plains region and $\mathrm{Lu}$, at first migrated eastwards to this point under Chu's stress, and then destroyed by $\mathrm{Lu}$, finally annexed by Qi in turmoil.

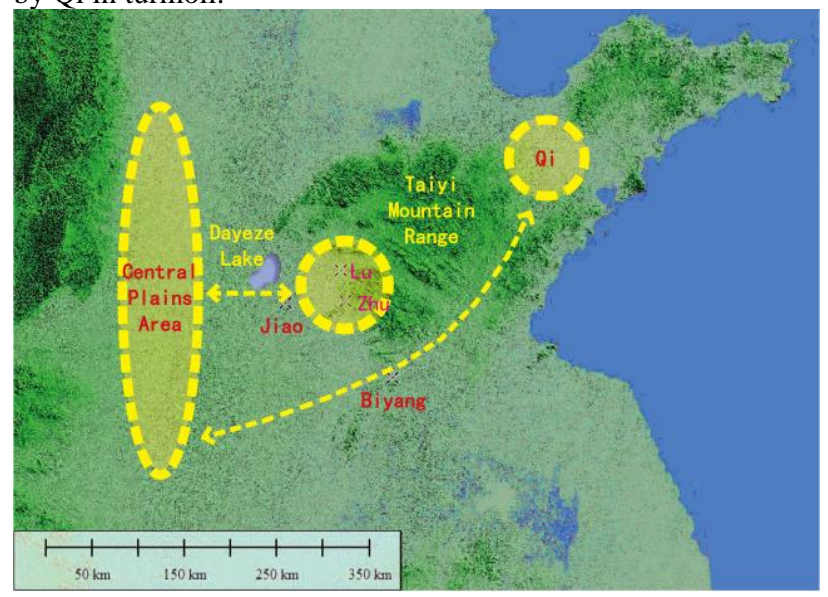

Figure 22. The situation analysis of Biyang and Jiao

Overall, survey region situated between Dayeze Lake and Taiyi mountains, relatively independent. However, Biyang and Jiao were both small country and located on the traffic arteries linked to the surrounding countries. Traditionally, regions like this generally had territorial divisions, and small countries there couldn't get rid of the fate of perishing. The fate of the two countries reflected the unrest of the geographical unit transfer parts was portrayal of the change in national strength contrast. Nowadays, Jiao is close to the border of Jining and Heze; Biyang is located in the southern tip of Zaozhuang, close to Shandong and Jiangsu border, both are still at the boundary of administrative divisions.

\subsection{Xue and Teng: Geographical Advantage and Culture Prosperity}

As small plain country, Xue and Teng were mostly flat with few hills and poor defensive performance (Fig. 23), but both country enjoyed vast fertile plains for a long period of time. On one hand, they located in the geographical unit were surrounded by $\mathrm{Lu}$ and Zhu, hardly any external turmoil; on the other hand, due to the profound cultural background and the doctrine of the moderation way of life, Kings would not be allowed to attack small states with virtue and honour, like Xue and Teng.

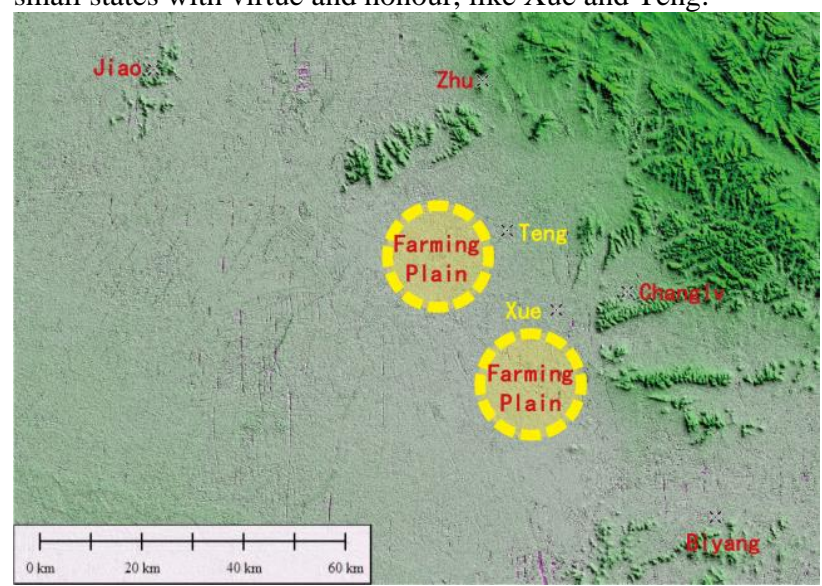

Figure 23. The situation analysis of Xue and Teng

Xue was stronger than Teng, however, Teng implemented "kind governance" and ruled for a longer time instead. Reflected vassal kings sought reputation as well as pursuit interests of the state, during the Spring and Autumn Period.

\section{CONCLUSION: THE MODE OF THE VASSAL STATE'S CITY GROUP AND CAUSES}

Ancient times, numerous ancient states set up in the appropriate areas, as some countries' congenital conditions were more suitable for development, they strengthened gradually, which constituted the capital city of the original geographical differences. Into the dispute period under the jungle law, fighting and defensing became main melody, city construction emphasized on defense system and enhancing fighting capacity; yet, no country could get rid of innate geographical conditions. Under this circumstance, in the Spring and Autumn Period, feudal states acted of one's own free will, the relationships between cities contained the one within and between vassal states. Within vassal state relationships included economic support, entrenching each other and protecting the country together. Meanwhile, strategic defensing, scrambling for resources and geographical location comprised of the competition between vassal states.

$\mathrm{Lu}$, as the strongest state in this area, had ability to locate the country on the plain and constructed a defense system composed of several cities. For the rest weak power, they had to strategically situated, with the purpose of self-preservation. To sum up, if the comparison of comprehensive national strength changed or new external force rose, there would be three situations for small states: gave up favorable geographical position and moved to the corner of the ground, attached the power to survive or perished under no choice. As this area, Zhu relocated capital to develop new land forced by $\mathrm{Lu}$, however, unexpected became strong gradually. Xiaozhu had to give up agricultural advantage, and moved to the basin beside the edge of mountainous region in order to avoid $\mathrm{Lu}$ after dependence Qi. Lan, Xue and Teng all located between Zhu and Lu. In the dispute between the two country, Lan paid allegiance to $\mathrm{Lu}$, in an awful congenital condition; Xue and Teng kept the country a long time, relying on good reputation and excellent farming conditions. Biyang and Jiao located at the channel contacted south region of Shandong with outside world, suffered most territorial dispute, and destroyed earliest. Everyone got its own corresponding historical and geographical reasons.

In the agrarian age, the political centers and agricultural areas WEre interdependent, giving priority to the development of political cities. Transformation of capitals' space layout was actually the process of carving up farming plains, the powerful states occupy favorable geographical position, and the small countries would be encroached and annexed gradually. Capital Construction reflected comprehensive national strength layout, limited by natural geographical factors, and influenced not only the residence of a country's people but also their fate.

\section{REFERENCES}

Yuzhen Yang, 2008a. The rechanneling of Yellow River and the impact on the development of the Chinese nation. Journal of Paleogeography (Chinese Edition), Vol.04, pp. 436-437.

Yongsheng Guo, 1990a. Changes of the lakes in Shandong in the history. Transactions of Oceanology and Limnology, Vol.03, pp. 18,17 . 
State Administration of Culture Heritage, 2009. Cultural Relics Atlas China (Shandong Volume), Culture Relics Press, Beijing, China.

Xiantang Wang, 2007. Textual Research of Ancient State in Shangdong, Qingdao Publishing House, Qingdao, China, pp. 66.

Baizhong Wang, 2000a. A Preliminary Study of Mausoleum Sacrifice and Ancestral Temple in Han dynasty. Journal of Anshan Normal University, Vol.12, pp. 18-20.

Revised July 2015 